\title{
Antifungal Activity of Hyptis spicigera Methanol Leaf Extract and Flavonoid Fraction
}

\author{
${ }^{1}$ ADAMU, K; ${ }^{1}$ MUSA, H; ${ }^{2}$ ALIYU, AB; ${ }^{1 *}$ MUSA, AO \\ ${ }^{* 1}$ Department of Botany, Faculty of Life Sciences, Ahmadu Bello University, Zaria, Nigeria \\ ${ }^{2}$ Department of Chemistry, Faculty of Physical Sciences, Ahmadu Bello University, Zaria, Nigeria \\ *Corresponding Author Email: ayioiza@gmail.com; Tel: +2347038086164
}

\begin{abstract}
Control of plant fungal diseases using synthetic fungicides continue to cause major problems to human health and the entire ecosystem. The aim of this research was to investigate the phytochemical and antifungal properties of Hyptis spicigera methanol leaf extract and flavonoid fraction on Aspergillus and Fusarium species, with a view to uncovering effective bio-fungicides for development as substitutes to chemical fungicides. Phytochemical screening revealed the presence of sterols and triterpenes, cardiac glycosides, flavonoids, tannins and alkaloids. The quantitative analysis showed that saponin $(690 \mathrm{mg} / \mathrm{g}$ GAE), phenolics $(220 \mathrm{mg} / \mathrm{g}$ GAE) and flavonoids $(140 \mathrm{mg} / \mathrm{g} \mathrm{GAE})$ were found to be in high concentration. The antifungal effects of $H$. spicigera methanol extract on $F$. graminearum $(21 \mathrm{~mm})$ was significantly $(\mathrm{p}<0.05)$ higher than the control fungicide (Mancozeb). Similarly, the flavonoid fraction was more effective on A. parasitic $(18 \mathrm{~mm})$ than the control fungicide used. The extract and fraction exhibited MIC with range 3.13-12.5 mg/mL and MFC 6.25-12.5 $\mathrm{mg} / \mathrm{mL}$, indicating promising antifungal efficacies against $A$. flavus and $F$. graminearum. Our findings have revealed that $H$. spicigera flavonoid rich fraction has potential for development as effective bio-fungicide to control plant fungal diseases of the Aspergillus and Fusarium species.
\end{abstract}

\section{DOI: https://dx.doi.org/10.4314/jasem.v25i7.10}

Copyright: Copyright $\odot 2021$ Adamu et al. This is an open access article distributed under the Creative Commons Attribution License (CCL), which permits unrestricted use, distribution, and reproduction in any medium, provided the original work is properly cited.

Dates: Received: 10 May 2021; Revised: 28 June 2021; Accepted: 01 July 2021

Keywords: Antifungal, Hyptis spicigera, flavonoid fraction, Aspergillus, Fusarium

Plant fungal diseases are controlled usually by synthetic chemical fungicides and sometimes by cultural practices. This is because chemical fungicides are found as effective method against fungal diseases. However, they constitute major health problems to the entire ecosystem due to acute toxicity and long degradation period. Moreover, the indiscriminate use of chemical fungicides has resulted to pathogen resistance due to selective pressure (Shukla, 2013; Bhagwat; Datar, 2014). Hence, the need for safe, effective and environmentally sustainable approach to controlling plant fungal diseases especially with the $25-50 \%$ loss in agricultural crops due to fungal infections (Chuang et al., 2007; Zaker, 2014). Fungal genus such as the Aspergillus consists of over 200 species with $95 \%$ of its infections caused by $A$. fumigatus, A. flavus, A. niger (Anaissie et al., 2009). Fusarium is also an economically important genera of plant fungi that infects agricultural produce according to crops, geography and environmental conditions (Longrieco et al., 2002; Vander Lee et al., 2015). Thus, the search and development of effective biopesticides from plants is necessary to overcome the loss in agricultural crops due to fungal infections. Previous report showed that numerous plant extracts have exhibited potent antifungal activities (Masih et al., 2014; Wuyep et al., 2017). Hyptis spicigera (Lamiaceae family) is a flowering plant, erect and annual herb with about 300 to 400 species. The plant is frequently grown as a food crop for its seeds in tropical West Africa. It is aromatic and commonly known as bush mint found in tropical North and South America. Hyptis spicigera is used in Nigerian traditional medicine for gastrointestinal disturbances, wounds, skin infections and insect bites (Patricia et al., 2014). Several species of Hyptis genus have similar ethnopharmacology with related phytochemical profile (McNeil et al., 2011). Previous phytochemistry of the Hyptis genus showed that $\beta$ sitosterol, oleanolic acid and urs-12-en-3 $\beta$-ol-27-oic acid have been isolated from the roots of Hyptis suaveolens (Misraet al., 1981). The report by Moreira et al. (2010) also showed that $H$. suaveolens essential oil from Brazil contain largely eucaliptol (48\%) with antifungal activity on Aspergillus species. However, H. spicigera essential oil from Nigeria was found to contain $\beta$-caryophyllene (68\%) as major component (Onayade et al., 1990). In this study, we report the quantitative analysis of $H$. spicigera methanol extract and subsequent isolation of flavonoid fraction with evaluation of antifungal activity on Aspergillus and Fusarium species. This is with a view to uncovering 
biopesticides for effective control of plant fungal diseases of the Aspergillus and Fusarium species.

\section{MATERIALS AND METHODS}

Plant material: Hyptis spicigera Lam. fresh leaf was collected within Zaria environs located between Latitude $11^{\circ} 55^{\prime \prime} \mathrm{N}$ and Longitude $7^{\circ} 99^{\prime \prime} \mathrm{E}$. The leaf was identified at the herbarium unit of the Department of Botany, Ahmadu Bello University Zaria, where a Voucher number (ABU2050) was deposited.

Preparation and extraction of plant material: Hyptis spicigera fresh leaves were dried at room temperature for 21 days and grinded into fine powder using grinding machine. The powdered sample was weighed and extracted using the method described by Kokate $e t$ al. (2002) with some modifications. Briefly, $250 \mathrm{~g}$ of powdered plant material was extracted with methanol (2L) using cold maceration at room temperature $\left(25^{\circ} \mathrm{C}-36^{\circ} \mathrm{C}\right)$ for $24 \mathrm{~h}$. The filtrate was concentrated to dryness at room temperature and kept in the desiccator for further analyses.

Qualitative phytochemical screening: The leaf extract was tested for saponins, cardiac glycoside, flavonoids, tannins, sterols and triterpenes and alkaloids using standard methods (Trease and Evans, 2009).

Quantitative phytochemical screening: The leaf extract was subjected to various quantitative analysis for total phenolics content, total flavonoids contents, total alkaloids, total tannins and total saponins content: The total phenolics content (TPC) and total tannins content (TTC) were measured spectroscopically by Folin-Ciocalteu colometric method, using Gallic acid as standard, expressed as Gallic Acid Equivalent (GAE) per gram of sample (Alhakmani et al., 2013; AfifyAel-M et al., 2012). However, the total flavonoids contents (TFC) was determined by aluminum chloride Colometric assay and expressed as $\mathrm{mg} / \mathrm{g}$ Quercetin Equivalent (QE) (Zhishen et al., 1999). The total alkaloids content (TAC) was determined by spectroscopic method based on reaction with bromocresol green (BCG) and expressed in $\mathrm{mg} / \mathrm{g}$ Atropine Equivalent (AE) (Shamsa et al., 2008; Sharief et al., 2014). Then, the total saponins content (TSC) was determined as described by Makkar et al. (2007). Diosgenin $(0.5 \mathrm{mg} / \mathrm{mL})$ was used for standard calibration curve. The total saponins concentration was expressed as mg/g Diosgenin Equivalent (DE).

Flavonoid isolation and TLC chromatographic profile: Flavonoid was isolated from the methanol extract using standard method as described by Woo et al. (1980) (Figure 1). The fraction was spotted on a silica gel coated plate and ran in a TLC tank using butanol-acetic-acid-water BAW (10:1:1) as solvent system. Specific flavonoid chemical test was carried out using aluminum chloride as spray reagent for flavonoid detection on the TLC plates. The plate was sprayed with $1 \%$ ethanol solution of aluminum chloride and the appearance of a yellow or red fluorescence in a long wavelength $(360 \mathrm{~nm})$ of UV light confirms flavonoids.

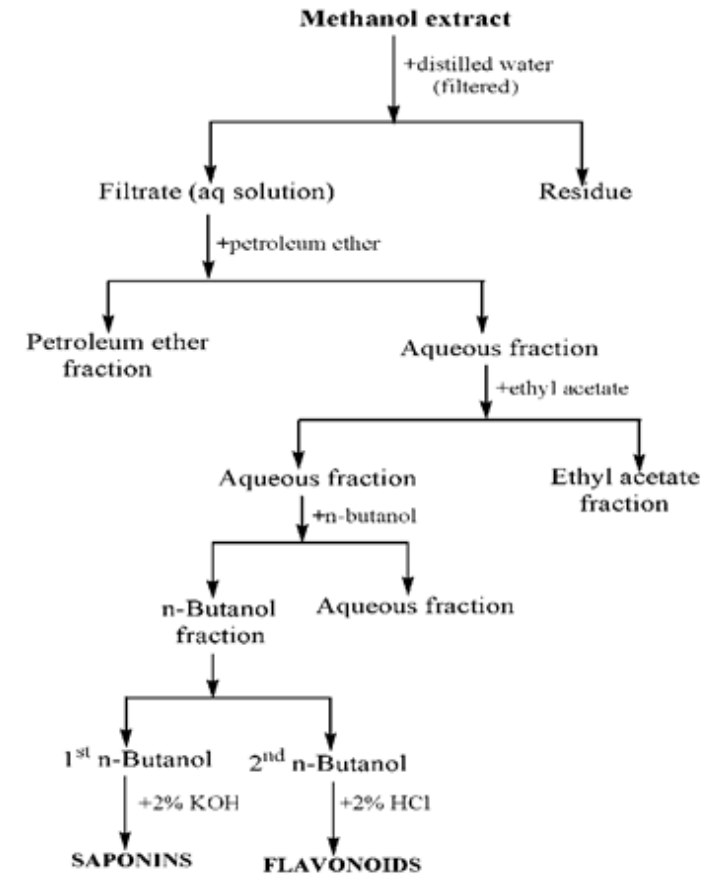

Fig. 1: Fractionation procedure for flavonoid isolation as reported by Woo et al (1990)

Fungal isolates and preparation of inoculum: Four different species each of Aspergillus and Fusarium identified by Innovative Medicine Initiative (IMI) was used for the study. Already, cultured isolates were collected from the Department of Crop Protection, Ahmadu Bello University, Zaria. The four species of Aspergillus used are: A. flavus, A. niger, A. parasiticus and $A$. fumigatus. The four species of Fusarium used are: $F$. verticilloides, $F$. graminerum, $F$. oxysporum and $F$. proliferatum. Potato Dextrose Agar (PDA) was used for the growth of the fungi species and was prepared according to the manufacturer, autoclaved at $121^{\circ} \mathrm{C}$ for $15 \mathrm{~min}$. The prepared medium $(20 \mathrm{~mL})$ each was dispensed in universal bottle with caps covered and kept in the refrigerator prior to usage. The spores from the surface of the plates was collected with inoculating needle and suspended in normal saline solution $(10 \mathrm{~mL})$. The mixture was homogenized, $10 \%$ Tween-20 (2 mL) was added and heavy particles were allowed to settle down and gradually decanted into a sterile tube. The suspension was adjusted to 0.5 McFarland standard equivalent to the turbidity of the suspension by a spectrophotometer at a wavelength of 
$530 \mathrm{~nm}$ to obtain a final concentration that will match 0.5 McFarland standard for mold base on the optical density of the solution $\left(0.4-0.5 \times 10^{6}\right) \mathrm{CFU} / \mathrm{mL}$ (EUCAST, 2014).

Antifungal sensitivity test: Agar well diffusion method was used for the screening on test organism. The test inoculum $(0.1 \mathrm{~mL})$ was smeared across the petri dish. The extract $(0.5 \mathrm{~g})$ was dissolved in $20 \%$ DMSO (10 $\mathrm{mL}$ ) resulting to concentration of the extract to be 50 $\mathrm{mg} / \mathrm{mL}$. The prepared extract $(0.1 \mathrm{~mL})$ was introduced into the well and incubated at $30^{\circ} \mathrm{C}$ for 7 days after which the plates were observed for zone of inhibition, and measured with a meter rule and documented excluding the diameter of the well (CLSI, 2014) A positive control Mancozeb (Fungicide) and a negative control which are Normal Saline and 20\% DMSO were set to account for their inhibitory action.

Minimum inhibitory concentration (MIC): The MIC was determined using the broth dilution method; Potato Dextrose Broth (PDB) was prepared as prescribed by the manufacturer. Two-fold serial dilution of the extract and fraction were carried out in the sterile broth to obtain a concentration of 50 $\mathrm{mg} / \mathrm{mL}, 25 \mathrm{mg} / \mathrm{mL}, 12.5 \mathrm{mg} / \mathrm{mL}, 6.25 \mathrm{mg} / \mathrm{mL}, 313$ $\mathrm{mg} / \mathrm{mL}$ and $1.67 \mathrm{mg} / \mathrm{mL}$. One loop full of the already prepared standard inoculum was introduced into each of the test tube containing varied concentration of the extracts dissolved in the PDB was done and incubation was carried out for 7 days at a temperature of $30^{\circ} \mathrm{C}$. The MIC was read as the test tube having the least concentration of the extract with no sign of sporulation of fungi; this could easily be seen from the surface of each tube as the spores if present will show visible sign of colored spores depending on the species (CLSI, 2014).

Minimum fungicidal concentration (MFC): Potato Dextrose Agar (PDA) was prepared, the content of the MIC starting from the test tube which the MIC were recorded and those with increase concentration of the extract in the sterile dilution were sub-cultured onto prepared medium. The plates were incubated at $30^{\circ} \mathrm{C}$ for 7 days after which the plates were observed for colony growth. The plate with the least concentration of the extract without colony growth is referred to as the minimum fungicidal concentration (CLSI, 2014).

Data analysis: Quantitative analysis of phytochemicals and the average mean zone of inhibition of each extract and the controls were subjected to One-way Analyses of Variance (ANOVA), where significant Duncan's Multiple Range Test was used to separate the means using SPSS version 20.

\section{RESULTS AND DISCUSSION}

Qualitative and quantitative phytochemical analysis: The qualitative screening of phytochemicals from $H$. spicigera leaf methanol extract showed numerous secondary metabolites (Table 1). The presence of these phytochemicals implied that the plant could be a good source of potent therapeutic agents. Previous phytochemical screening shows similar profile with Hyptis species as reported by Sharma and Tripathi (2008). The quantitative evaluation revealed that saponins $(690 \mathrm{mg} / \mathrm{g})$ had significantly higher concentration than other phytochemicals (Table 1). The saponin concentration of $690 \mathrm{mg} / \mathrm{g}$ Diosgenin Equivalent (DE) indicated that the plant is rich in saponin glycosides. The high concentration of saponins is a pointer for broad range antifungal agents capable of controlling plant mycotic infections (Ladan et al., 2014). Previous report attributed the role of saponins from plant extract on lyses of fungal spores and subsequent death of the cells (Masih et al., 2014). The phenolics content (220 mg/g GAE) from $H$. spicigera leaf methanol extract indicated promising antimicrobial agents, because phenolics compounds at very little concentration inhibits the growth and sporulation of several fungi species leading to fungistatic or fungicidal in fungal species (Beatriz et al., 2018).

Table 1: Phytochemical analysis of H.spicigeraof methanol leaf extract

\begin{tabular}{|c|c|c|c|}
\hline Phytochemicals & Test & Qualitative & Quantitative (mg/g) \\
\hline Sterols and triterpenes & Salkowski & + & \\
\hline Cardiac glycoside & Kella-killiani & + & \\
\hline \multirow[t]{2}{*}{ Saponins } & Frothing & + & $690 \pm 0.33$ \\
\hline & Haemolysis & + & \\
\hline \multirow{2}{*}{ Flavonoids } & Shinoda & + & $140 \pm 0.33$ \\
\hline & Ferric Chloride & + & \\
\hline \multirow[t]{2}{*}{ Tannins } & Lead-Acetate & + & $20 \pm 0.17$ \\
\hline & Bromine-water & + & \\
\hline \multirow[t]{3}{*}{ Alkaloids } & Mayer's & + & $90 \pm 0.13$ \\
\hline & Dragendorf's & + & \\
\hline & Wagner's & + & \\
\hline Phenolics & & & $220 \pm 0.13$ \\
\hline
\end{tabular}


Plant flavonoids possess specific bioactivities against pathogenic microbial agents (Kumar and Pandey, 2013). Thus, H. spicigera leaf methanol extract contains flavonoids (140 mg/g GAE) indicating the important role as antifungal therapeutic agents. The effects of flavonoids on fungal pathogens reported previously suggest their structural and chemical diversity as the basis of therapeutic potentials (De Conti Lourenço et al., 2013). The alkaloids quantification was low ( $90 \mathrm{mg} / \mathrm{g}$ Atropine Equivalent) nevertheless, alkaloids are associated to intercalate into the microbial cell wall component and cause disruption (Cowan, 1999). Antifungal activity of $H$. spicigera extract and flavonoid fraction: The antifungal effects of methanol extract and flavonoid fraction are presented (Table 2). Five of the eight fungal species were susceptible to both the extract and fraction. The range for zone of growth inhibitions for methanol extract $(18-21 \mathrm{~mm})$ and flavonoid fraction
(14.33-18.33 $\mathrm{mm})$ as presented. The effect of methanol extract on $F$. graminearum with higher antifungal activity $(21 \mathrm{~mm})$ indicates the potency of the crude extract, but no statistically significant $(\mathrm{p} \geq$ 0.05) difference with flavonoid fraction and the control drug. However, it was observed that the antifungal activity of both extract and fraction was significantly ( $\mathrm{p} \geq 0.05$ ) more potent on A. parasiticus and $F$. oxysporum than the control drug (Table 2 ). The resistance of $A$. parasiticus and $F$. oxysporum to the control fungicide (Mancozeb) depicts phytoconstituents from $H$. spicigeraas effective biofungicides. Previous report showed that Aspergillus sp. was susceptible to Barringtonia racemosa methanol leaf extract with only $31.3 \%$ inhibition (Hussin et al., 2009). Thus, the susceptibility of these fungal species to $H$. spicigera extract and fraction might be due to synergistic interactions of phytoconstituents.

Table 2: Antifungal activity of $H$. Spicigera methanol extract and flavonoid fraction

\begin{tabular}{llll}
\hline \multicolumn{4}{c}{ Tone of inhibition $(\mathbf{m m})$} \\
\hline Fungal species & Methanol Extract & Flavonoid Fraction & Control (Mancozeb) \\
\hline A. flavus & $18.00 \pm 0.33^{\mathbf{b}}$ & $16.67 \pm 0.33^{\mathbf{c}}$ & $20.00 \pm 1.16^{\mathbf{a}}$ \\
A. fumigatus & $18.33 \pm 0.88^{\mathbf{b}}$ & $14.33 \pm 0.33^{\mathbf{c}}$ & $22.67 \pm 0.88^{\mathbf{a}}$ \\
A. parasiticus & $18.33 \pm 0.88^{\mathbf{a}}$ & $18.33 \pm 0.33^{\mathbf{a}}$ & $0.00 \pm 0.00^{\mathbf{c}}$ \\
A. niger & $0.00 \pm 0.00^{\mathbf{b}}$ & $0.00 \pm 0.00^{\mathbf{b}}$ & $19.33 \pm 0.88^{\mathbf{a}}$ \\
F. graminearum & $21.00 \pm 0.00^{\mathbf{a}}$ & $17.67 \pm 0.33^{\mathbf{c}}$ & $18.33 \pm 1.45^{\mathbf{b}}$ \\
F. proliferatum & $0.00 \pm 0.00^{\mathbf{b}}$ & $0.00 \pm 0.00^{\mathbf{b}}$ & $21.00 \pm 0.57^{\mathbf{a}}$ \\
F. oxysporum & $18.00 \pm 0.58^{\mathbf{a}}$ & $17.67 \pm 0.33^{\mathbf{b}}$ & $0.00 \pm 0.00^{\mathbf{c}}$ \\
F. verticilloides & $0.00 \pm 0.00^{\mathbf{b}}$ & $0.00 \pm 0.00^{\mathbf{b}}$ & $22.00 \pm 0.58^{\mathbf{a}}$ \\
\hline \multicolumn{4}{c}{ Mean with the same superscript along each row are not significantly different at $\mathbf{p} \geq 0.05$}
\end{tabular}

The minimum inhibitory concentration (MIC) represents the low concentration required to inhibit fungal growth. Low MIC translates to potent antifungal activity of the extract or fraction being evaluated. The $H$. spicigera methanol extract demonstrated $\mathrm{MIC}_{\mathrm{m}}$ of $12.5 \mathrm{mg} / \mathrm{mL}$ on all test organisms. However, flavonoid fraction exhibited $\mathrm{MIC}_{\mathrm{f}}$ range of $3.13-12.5 \mathrm{mg} / \mathrm{mL}$ indicating most potent antifungal activity (Figure 2 ). This revealed that the flavonoid rich fraction is effective antifungal agent on $A$. flavus and $F$. graminearum more than the methanol crude extract. Previous report on antifungal efficacy and mechanisms of flavonoids indicated that medicinal plants containing flavonoids are safe antifungal agents that demonstrated enormous therapeutic potentials through disruption of plasma membrane as well as inhibition of cell wall formation, cell division or protein synthesis (Al Aboody and Mickymaray, 2020). The minimum fungicidal concentration (MFC) is the lowest concentration that can completely kill the fungal species being evaluated. Thus, lowest MFC values indicate therapeutic properties of extracts under study. The methanol extract displayed $\mathrm{MFC}_{\mathrm{m}}(12.5 \mathrm{mg} / \mathrm{mL})$ for all fungal organisms tested. However, the flavonoid fraction demonstrated the lowest $\mathrm{MFC}_{\mathrm{f}}$ of $6.25 \mathrm{mg} / \mathrm{mL}$ indicating most potent fungicide on $F$. graminearum (Figure 2). This finding has revealed the application of $H$. spicigera flavonoid fractions as effective biofungicide to control of plant fungal diseases based on Aspergillus and Fusarium species.

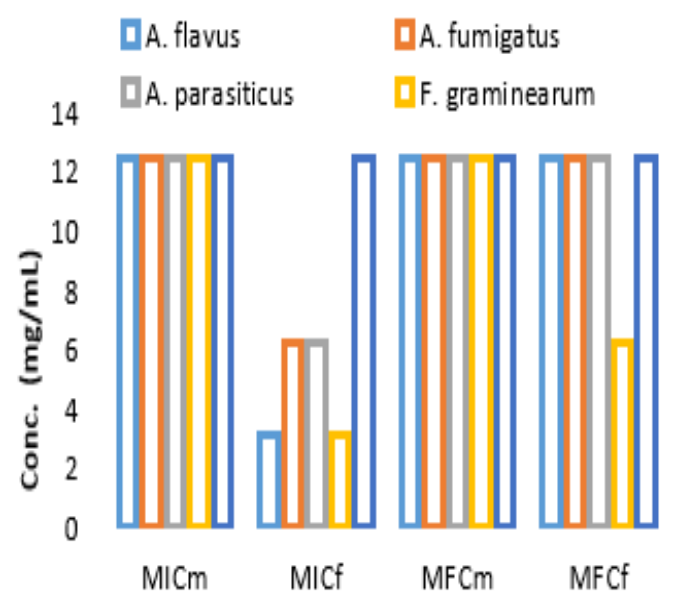

Fig 2: MIC /MFC of $H$. specigera methanol extract and flavonoid fraction 
Conclusion: H. spicigera leaf methanol extract was found to contain phytochemicals such as saponins, phenolics and flavonoids in high concentration. The flavonoid rich fraction isolated from methanol extract demonstrated significant antifungal efficacies on $A$. flavus and $F$. graminearum. Our findings have revealed the potential of $H$. spicigera flavonoid fraction for development of bio-fungicides to control plant fungal diseases especially based on Aspergillus and Fusarium species.

Acknowledgement: The authors sincerely appreciate the contribution of Dr. Mikhail S.A. of Nigerian Institute of Leather Science and Technology, Zaria for his contribution toward this research by making it a reality. Our appreciation also goes to Mallam Kabir Ibrahim of the Department of Pharmacognosy, Faculty of Pharmaceutical Sciences, Ahmadu Bello University, Zaria.

\section{REFERENCES}

Afify, AEMR; El-Beltagi, HS; El-Salam, SM; Omran, AA (2012). A biochemical change in phenols, flavonoids, tannins, vitamin E, $\beta$-carotene and antioxidant activity during soaking of three white sorghum varieties. Asian Pac. J. Trop. Biomed. 2(3):203-209

Al Aboody, MS; Mickymaray, S (2020). Anti-fungal efficacy and mechanisms of flavonoids. Antibiotics. 9: 45

Alhakmani, F; Kumar, S; Khan, SA (2013): Estimation of total phenolics content, in vitro antioxidant and anti-inflammatory activity of flower of Moringa oleifera. Asian Pac. J. Trop. Biomed.3 (8): 623-627

Anaissie, EJ; Kuchar, RT; Rex, JH; Francesconi, A; Kasai, M; Müller, FM; Lozano-Chiu, M; Summerbell, RC; Dignani, MC; Chanock, SJ; Walsh, TJ (2009). Fusariosis associated with pathogenic Fusarium species colonization of a hospital water system: a new paradigm for the epidemiology of opportunistic mold infections. Clin. Infect. Dis. 33: 1871-1878

Beatriz, P; Luisa, M; Calvarro1, DP; Alberto, E; Maria, L; Tello, EP; Arancha, GG (2018). Antifungal effects of phenolics extract from industrial residues of Aloe vera. Spanish J. Agric. Res. 16 (4):1010-1018

Bhagwat, MK; Datar, AG (2014). Antifungal Activities of herbal extracts against plant pathogenic fungi. Arch. Phytopathol. Plant Protect. 47 (8): 959-965

Clinical and Laboratory Standard Institutes (CLSI) (2014): Document M39-A3. Analysis and Presentation of Cumulative Antimicrobial Susceptibility Test Data. Approved Guideline, Third Edition.CLSI, 940 West Valley Road, Suite 1400; Wayne, Pennsylvania. USA

Cowan, MM (1999). Plant products as antimicrobial agents. Clin. Microbiol. Rev. 12: 564 - 582.

De Conti Lourenço, RM; da Silva Melo, P; de Almeida, ABA (2013). Flavonoids as antifungal agents. In: Razzaghi-Abyaneh, M; Rai, M (eds), Antifungal Metabolites from Plants. SpringerVerlag Berlin Heidelberg, pp. 283-300

EUCAST (2014). European Committee on Antimicrobial Susceptibility Testing of isavuconazole susceptibility in Aspergillus: comparison of results for inoculum standardization using counting versus optical density. Antimicrob. Agents Chemother. 58 (11): 6432-6436

Hussin, NM; Muse, R; Ahmad, S; Ramli, J; Mahmood, M; Sulaiman, MR; Shukor, MYA; Rahman, MFA; Aziz, KNK (2009). Antifungal activity of extracts and phenolic compounds from Barringtonia racemosa L. (Lecythidaceae). Afr. J. Biotech. 8 (12): 2835-2842

Ladan, Z; Amupitan, JO; Oyewale, AO; Ayo, RG; Temple, E; Ladan, EO (2014). Phytochemical screening of the leaf extract of Hyptis spicigera plant. Afr. J. Pure Appl. Chem. 8(5): 83-88.

Longrieco, A; Mule, G; Moretti, A; Bottalico, A (2002). Taxogenic Fusarium species and mycotoxin associated with maize ear rot in Europe. J. Plant Pathol. 108: 597-609

Makkar, HP; Siddhuraju, P; Becker, K (2007). Methods of Molecular Biology: Plant secondary metabolites, Totowa, Human Press; 93-100

Masih, H; Peter, JK; Tripathi, PA (2014). Comparative evaluation of antifungal activity of medicinal plant extracts and chemical fungicides against four plant pathogens. Int. J. Curr. Microbiol. Appl. Sci. 3(5): 97-109

McNeil, M; Facey, P; Porter, R (2011). Essential oils from the Hyptis genus- A Review (1909-2009). Nat. Prod. Comm. 6(11): 1775-1796 
Misra, TN; Singh, RS; Ojha, TN; Upadhyay, J (1981). Chemical constituents of Hyptis suaveolens. Part I. spectral and biological studies on a triterpene acid. J. Nat. Prod. 44 (6): 735-738

Mohanta, TK; Patra, JK; Rath, S K Pal, D. K. and Thatoi, H. N. (2007). Evaluation of antimicrobial activities and phytochemical screening of oil and nuts of Semicarpus anacardium L. Sci. Res. Essent. 2 (11): 486-490

Moreira, ACP; Lima, EO; Wanderley, PA; Carmo, ES; de Souza, EL (2010). Chemical composition and antifungal activity of Hyptis suaveolens (L.) Poit leaves essential oil against Aspergillus species. Braz. J. Microbiol. 41: 28-33

Onayade, OA; Looman, A; Scheffer, JJC; Svendsen, AB (1990). Composition of the herb essential oil of Hyptis spicigera Lam. Flavour Fragr. J. 5: 101105

Patricia, C E; Aldo, FC; Mayela, YR; Elvira, G; Laura, A; Maria, RC (2014). Volatile constituents identified in hexane extract of Citrus sinensis peel and anti-Mycobacterium tuberculosis activity of some of its constituents. J. Mex. Chem. Soc. 58 (4): 431-434

Shamsa, F; Hamidreza, M; Rouhollah, G; Mohammadreza, V (2008). Spectrophotometric determination of total alkaloids in some Iranian medicinal plants. Thailand J. Pharm. Sci. 32: 1720

Sharief, MD; Srinvasulu, A; Uma, MR. (2014). Estimation of alkaloids and total phenol in roots of Derris trifoliate L. and evaluation for antibacterial and antioxidant activity. Indian J. Appl. Res. 4 (5): $1-11$
Sharma, N; Tripathi, A (2008). Integrated management of postharvest Fusarium rot of gladiolus corms using hot water, UV-C and Hyptis suaveolens (L.) Poit Essential oil. Postharvest Biol. Tec. 47: 246-254

Shukla, AC (2013). Plant secondary metabolites as sources of post-harvest disease management: An overview. J. Stored. Prod. Postharvest Res. 4(1): 1-10

Trease, WC; Evans, WC (2009). Introductory to Pharmacognosy $16^{\text {th }}$ Edition. W.B. Saunders Publishers pp.196-394

Vander-lee, T; Zhang, H; Diepeningen, V; Waalwijik, AC (2015). Biogeography of Fusarium graminearum species complex and chemotypes: $A$ Review. Food Addit. Contam. 32: 453-460

Woo, SW; Shin, HY; Kang, KS (1980). Chemistry and pharmacognosy of flavone-C-glycosides from Ziziphus seeds. The Korean J. Pharmacog. 11(34): 141-148

Wuyep, PA; Musa, HD; Ezemokwe, GC; Nyam, DD; Silagtang, MD (2017). Phytochemicals from Agerantum conyzoides L. extracts and their antifungal activities against virulent Aspergillus spp. J. Acad. Ind. Res. 6: 32-39.

Zaker, M (2014). Antifungal evaluation of some plant extracts in controlling Fusarium solani, the causal agent of potato dry rot in vitro and in vivo. Int. J. Agric. Biosci. 3(4): 190-195

Zhisen, J; Megcheng, T; Jiaming, Wu (1999).The determination of flavonoids content in Mulberry and their scavenging effects on superoxide radical. Food Chem. 64: 555-559 